CUADERNOS DE ESTUDIOS GALLEGOS, LXI Núm. 127 (enero-diciembre 2014), págs. 279-298

ISSN: $0210-847 \mathrm{X}$

DOI: 10.3989/ceg.2014.127.09

\title{
TRANSFORMACIONES ARQUITECTÓNICAS Y URBANAS EN LA CIUDAD DE SANTIAGO DE COMPOSTELA: EL TRIUNFO DEL GUSTO ECLÉCTICO Y LOS CRITERIOS HIGIENISTAS (1868-1931)*
}

\author{
Iván Moure Pazos \\ Università di Bologna
}

\footnotetext{
"El presente artículo se enmarca dentro del Proyecto titulado Laboratorio di Ricerca sulle Città
} (Istituto di Studi Superiori. Università di Bologna). 


\section{TRANSFORMACIONES ARQUITECTÓNICAS Y URBANAS EN LA CIUDAD DE SANTIAGO DE COMPOSTELA: EL TRIUNFO DEL GUSTO ECLÉCTICO Y LOS CRITERIOS HIGIENISTAS (1868-1931)}

\section{RESUMEN}

El presente artículo, trata de ser un fresco de las principales intervenciones urbanas y arquitectónicas surgidas en el llamado Santiago fin de siglo. El imperante gusto ecléctico, así como los nuevos criterios de salubridad, modificarán gran parte de la Compostela intra y extramuros con un claro fin: la creación de nuevos espacios de oxigenación, y la expansión urbana de los límites periféricos. Para ello, se llevaron a cabo importantes empresas arquitectónicas —no siempre respetuosas con su pasado medieval y barrocoque contribuyeron, de manera definitiva, a la imagen urbana de la Compostela contemporánea tal y como hoy la conocemos.

Palabras Clave: Santiago de Compostela, Arquitectura, Urbanismo, Eclecticismo.

\section{TRANSFORMACIÓNS ARQUITECTÓNICAS E URBANAS NA \\ CIDADE DE SANTIAGO DE COMPOSTELA: O TRIUNFO DO GUSTO ECLÉCTICO E OS CRITERIOS HIXIENISTAS (1868-1931)}

\section{RESUMO}

O presente artigo, pretende ser unha escolma das principais intervencións urbanas e arquitectónicas xurdidas no chamado Santiago fin de século. O imperante gusto ecléctico, así como os novos criterios de salubridade, modificarán gran parte da Compostela intra e extras muros cun claro fin: a creación de novos espazos de osixenación, e a expansión urbana dos límites periféricos. Para iso, leváronse a cabo importantes empresas arquitectónicas —non sempre respetuosas co seu pasado medieval e barroco- que contribuíron, de xeito definitivo, á imaxe urbana da Compostela contemporánea tal e como hoxe a coñecemos.

Palabras Clave: Santiago de Compostela, Arquitectura, Urbanismo, Eclecticismo.

\section{ARCHITECTURAL AND URBAN CHANGES IN THE CITY OF SANTIAGO DE COMPOSTELA: THE TRIUMPH OF ECLECTIC TASTE AND HYGIENIST CRITERIA (1868-1931)}

\section{ABSTRACT}

This article's goal is to be the snapshot of urban and architectonical interventions that arose at the end of the $19^{\text {th }}$ century in Santiago de Compostela. The dominant eclectic trend, as well as the salubrity's new criteria, will force the change of most of intra and extra-mural Compostela city, in an effort to achieve a target: the creation of oxygenation's new spaces, and the urban expansion of peripheral borderland. Chasing this change, relevant architectural facts got implemented, which contributed in a definitive way to the contemporanean Compostelan image, as we today know it, even though that changes weren't respectful to the baroque and medieval architectural past of city. KeY words: Santiago de Compostela, Architecture, Town Planning, Eclecticism. 
Recibido/Received: 25/11/2013

Aceptado/Accepted: 19/08/2014

\section{INTRODUCCIÓN}

$\mathrm{E}$

ntre 1868 y 1931 —coincidiendo con la reactivación universitaria y el asentamiento del culto jacobeo de manera institucionalizada y oficializada- se llevarán a cabo en Santiago de Compostela importantes reformas arquitectónicas y urbanísticas que modificarán su entramado histórico y periférico [fig. 1] $]^{1}$. Por entonces, la ciudad se modernizaba al calor de dos nuevas mejoras urbanísticas de saneamiento y abastecimiento poblacional que potenciaban las nuevas transformaciones urbanas y arquitectónicas a tratar: la introducción del moderno alumbrado público y el asentamiento de la red de abastecimiento de aguas potables para los particulares.

Respecto a la primera mejora, apuntar, que si bien es cierto, ya había comenzado su tímida andadura en 1822 con la rústica iluminación de aceite ${ }^{2}$, no fue

\footnotetext{
1 Antonio Bonet Correa, "Las ciudades gallegas en el siglo XIX", en María Victoria Carballo Calero (coord.), Arte y Ciudad. Ámbitos medieval, moderno y contemporáneo, Santiago, Fundación Caixa Galicia, 2000, págs. 180. Vid. Ramón Villares, "La ciudad de los dos Apóstoles (18751936)", en Ermelindo Portela Silva (coord.), Historia de la Ciudad de Santiago de Compostela, Santiago, Concello de Santiago, 2003, pág. 478.

2 Pablo Pérez Constanti, Notas Viejas Galicianas, Santiago, Xunta de Galicia, 1993, págs. 425426. "En Febrero de 1822 mandó el ayuntamiento colocar faroles en las inmediaciones de la cárcel, por lo mucho que interesa en las noches de oscuridad la vigilancia de los centinelas en la custodia de los presos, y en Octubre del propio año envió a la Diputación propuesta de arbitrios para establecer el alumbrado general en la Ciudad. Dos meses después estaban ya colocados unos trescientos faroles que habían hecho el maestro latonero D. Nicolás Losada y el Herrero Juan Pino". Andrés Rosende Valdés, Compostela (1780-1907): Una aproximación a la ciudad decimonónica, Santiago, Consorcio de Santiago y Teófilo Edicións, 2013, pág. 313. "No obstante, no nos engañemos. Hablamos de iluminación nocturna, pero de una iluminación de aceite, mortecina, escasa y, por si fuera poco, con unos puntos de luz muy distanciados entre sí. Y si a esto añadimos unas circunstancias climáticas como las de Santiago, con sus continuas lluvias y sus vientos, que con frecuencia arreciaban en violento temporal, apagando la llama o incluso rompiendo los cristales, fácilmente se puede concluir que el alumbrado en su primera fase no resultó muy eficaz, limitándose, en el mejor de los casos, a servir como punto de orientación".
} 
hasta 1874 cuando se introdujo el farol de gas $^{3}$, para, andando el tiempo, y - ya entrados en pleno siglo XX - evolucionar hacia el moderno farol eléctrico ${ }^{4}$. Esto repercutirá en una mejora de la circulación peatonal nocturna, por otra parte, urgente, debido al gran número de atropellos que se cometían con "nocturnidad y alevosía" sobre unas calles todavía mal pavimentadas que delimitaban una ciudad tipificada de onírica, taciturna, y penumbrosa ${ }^{5}$.

En cuanto al segundo acontecimiento importante, cabe aclararse que hasta bien entrado el siglo XIX, las fuentes eran el primordial abastecimiento de agua saneada con el que contaban la mayoría de los residentes compostelanos ${ }^{6}$. A partir de principios del XX, éstas empezarán a caer en desuso, en parte, debido a la subrogación de las viejas conducciones de piedra por otras menos endebles de

3 Alejandro Pérez Lugín, La casa de la Troya, Santiago, Universidad de Santiago, 2008, págs. 77-78. "[...] según el contrato previsor celebrado con el Ayuntamiento la Compañía del gas estaba exenta de la obligación de encender los faroles las noches que marcaba luna en el calendario.

- ¿Aunque llueva como ahora?

-Esto no es nada, así caigan chuzos.

¡Valiente poblacho! ¿Y allí habían ido a poner la Universidad? Era una desconsideración, "una mala sangre", según el vocabulario florido de la Mañitas. ¿Quién era capaz de estudiar en aquella cueva?". Andrés Rosende VALDÉs, Compostela (1780-1907)..., págs. 316-317. "El alumbrado por gas lució por primera vez en la noche del 7 al 8 de agosto de 1874, aunque sólo parcialmente, porque se había acordado que los faroles se encendiesen a medida que se fuesen colocando [...]".

${ }_{4}^{4}$ Pablo Pérez Constanti, Notas viejas..., pág. 427. "Contratado el servicio de alumbrado público por gas fluido, con la compañía Menéndez Valdés, de Gijón, en 1872, e inaugurado en la Alameda y en algunas calles el 8 de agosto de 1874, fue extendiéndose después por el resto de la población. Y éste ha sido el que hemos visto gozando hasta fecha reciente en que la aludida empresa —-subrogada ya desde 1 de Julio de 1895 por la Sociedad de Gas y Electricidad de Santiago— nos dio con suma cortesía al alumbrado eléctrico que seguiremos disfrutando; hasta que mañana una feliz y prodigiosa invención nos ofrezca otro de superiosísimas ventajas; pero...ese mañana no lo alcanzaremos nosotros". Vid. Pablo Costa Buján y Julián Morenas Aydillo, Santiago de Compostela.1850-1950, Santiago, COAG, 1989, pág. 37. Para más información, consultar: A. M. S. Obras y Urbanismo. Alumbrado Público. Memoria sobre el estudio de alumbrado eléctrico para la ciudad de Santiago con fuerza motriz del río Tambre. 1894. Donde se explica la ingente obra hidráulica ideada por el ingeniero Don Miguel Bruzos, con el propósito de abastecer de luz eléctrica a la ciudad santiaguesa. Asimismo consultar, A. M. S. Obras y Urbanismo Alumbrado Público. Concesiones para un nuevo emplazamiento de transformadores y tendido de cables. 1900. Ver también, A. M. S. Obras y Urbanismo. Alumbrado Público. Emplazamiento de casetas de transformadores y tendido de cables. Plano de línea de alta tensión subterráneo y de los transformadores colocados y de los que están por colocar.

5 Alejandro Pérez Lugín, La casa de la Troya..., pág. 82. Respecto a la oscuridad de la Compostela finisecular, resaltarse aquí a modo de guiño cómico el fragmento de la novela, donde el anónimo camarero se dirige al protagonista Gerardo Roquer y Paz diciéndole: "En cuanto a la oscuridad de las calles, hale de parecer muy bien cuando lleve aquí una temporadiña y se arme su choyo con alguna rapaza. Eso de los faroles apagados le es cosa de un concejal que conocía bien el pueblo y las conveniencias de los hombres, sobre todo de las personas serias".

6 Vid. Eduardo Beiras García, El arte del agua. Compostela y sus fuentes públicas monumentales de la edad media al siglo XX, A Coruña, InEditor, 2012. 


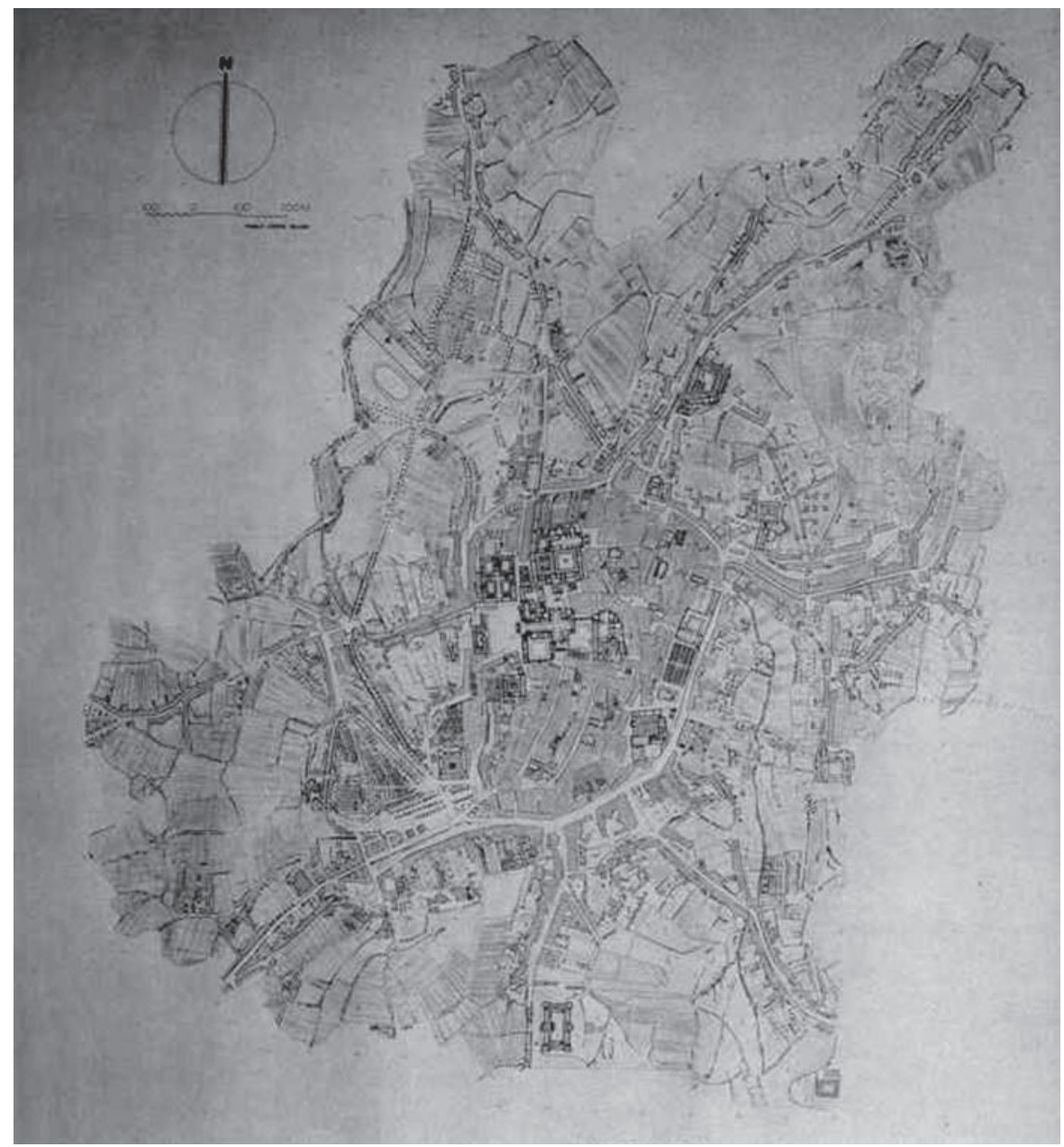

Fig. 1. Pablo Costa Buján. Plano de Santiago de Compostela. 1908. En: Juan Monterroso Montero, "El centro histórico. La creación de una conciencia cultural. El caso de Santiago de Compostela", en Actas do seminario: Centros históricos: pasado e presente, Porto, Faculdade de Letras da Universidade do Porto, 2011, pág. 58.

hierro, que surtirán a los hogares santiagueses de agua potabilizada ${ }^{7}$. Este hecho que fecundará en el desarrollo de una moderna red de alcantarillado encargada de gestionar la inmundicia de los particulares, poniéndose fin a la antigua costumbre de esparcir los desechos por el entramado callejero, en un período, cabe recordarlo, especialmente sensible a la pandemia infecciosa. Por consiguiente,

\footnotetext{
7 Pablo Costa Buján y Julián Morenas Aydillo, Santiago de Compostela..., pág. 37.
} 
no ha de extrañarnos que, en base a los mismos criterios sanitarios, se acuerde en 1893 la construcción de una necrópolis en Boisaca tras considerarse obsoleto el viejo cementerio de Santo Domingo de Bonaval de ubicación más céntrica y, por lo tanto, perjudicial para la ciudadanía.

Sendas mejoras de carácter técnico, facilitarán el abordaje de nuevas empresas arquitectónicas que, de manera explícita, modificarán el entramado urbano, tanto intra como extramuros, de la Compostela contemporánea.

\section{ESPACIOS INTRAMUROS}

En cuanto a los espacios intramuros, hablar en primer lugar de la supresión de las áreas porticadas ${ }^{8}$, que desde finales del siglo XVIII hasta la llegada de la Segunda República, deslustrarán diversas calles santiaguesas, tales como La Azabachería, Porta do Camiño, Porta da Pena, Zapateiros, Franco, Toral, Vilar ${ }^{9}$, o Rúa Nova. Tal desmaterialización urbana, se verá enfatizada, en numerosas ocasiones, por homogéneas reformas edilicias caracterizadas por una supresión de los cuerpos volados medievales, una marcada regularización de los vanos, o la inserción de características galerías de madera en los pisos superiores ${ }^{10}$. Conjuntamente a esto, Compostela se vestirá de gala para empedrar el grueso de su callejero histórico ${ }^{11}$ mediante la aplicación de un regular enlosamiento de granito ${ }^{12}$, como colofón final de lo que, con el transcurrir de los años, se convertirá

\footnotetext{
8 La supresión de esta tipología medieval obedece a tres razones fundamentales: los criterios higienistas, la imposición urbana de ensanchar la calle y la amenaza de desplome de algunos soportales en estado ruinoso.

9 Ramón Villares, "La ciudad de los Apóstoles...”, pág. 499. "Todavía en 1917 se aprobó la supresión de los soportales de la Rúa do Vilar, en su acera impar, hasta el número 67, a pesar de la oposición de algunos concejales que, con sensatez, alegaban que se debían conservar por razón de clima, pues facilitan la viabilidad en los frecuentes días de lluvia, sirven de refugio contra los atropellos de los carruajes y se utilizan para paseo en la época invernal".

${ }^{10}$ Carlos Martí Arís, "La ciudad histórica como presente" en Carlos Martí Arís (ed.), La ciudad histórica como presente. Un recorrido por la arquitectura de Santiago, Santiago, Consorcio de Santiago, 1995, pág. 34.

${ }^{11}$ Ramón Villares, "La ciudad de los Apóstoles...”, pág. 499. "Todavía a la altura de 1917 se produjo en la corporación municipal un acalorado debate sobre la reforma de la Rúa del Vilar que evidencia la existencia de posiciones ciertamente diferentes. Ante la propuesta de la comisión de Obras de echar un nuevo pavimento con cemento o asfalto, varios concejales, tanto conservadores como republicanos se oponen. Como señala el concejal conservador Pedro González, esta actuación haría desaparecer el aspecto artístico de la población, quitándole el sabor arquitectónico en que se funda el renombre la ciudad monumental".

${ }^{12}$ María del Pilar Cores Trasmonte, El urbanismo en Santiago de Compostela en el siglo XIX, Santiago, Universidad de Santiago, 1962, págs. 34-35. "Mantener siempre en buen estado la pavimentación supuso un problema económico para la ciudad, por la mano de obra y el material empleado, porque la mayor parte de la población esta empedrada en losas de granito, de coste bastante elevado. Aunque esto trae como ventaja una enorme duración, no evita las reparaciones
} 
en la imagen por excelencia de la poética santiaguesa, configurada mediante la fusión de su soporte viario con su ya establecido patrimonio edilicio ${ }^{13}$.

Paulatinamente, irá desapareciendo el quietismo urbano que caracterizaba el trazado medieval a la luz de nuevos postulados más activos de dinamización urbana basados en la apertura de nuevas arterias de comunicación vial que, de manera obligada, desembocarán en la destrucción de viejas manzanas ${ }^{14}$. Tales proyectos, como suele ocurrir, no siempre llegarán a consumarse, tal fue el caso de la dilatada Gran Vía (1888) propuesta por el arquitecto Manuel Prado y Vallo, consistente en la creación de una enorme calle a modo de vaso comunicante entre las Huérfanas y San Roque que vendría a expropiar:

\section{[...] todas las casas que exijan las líneas y el mayor ancho posible, que debe ser, desde luego, el que existe entre la Universidad y la línea de casas de la izquierda de la Calderería, dándose frente a la Universidad y al Instituto, adelantándolo a la línea de aquella, y expropiando también las casas hasta el arco de Mercado Viejo ${ }^{15}$.}

Dicha obra, vendría a segmentarse en dos áreas bien definidas, la primera desde las Huérfanas hasta las llamadas Cinco Calles, y la segunda desde este punto hasta San Roque ${ }^{16}$.

Pero si en agua de borrajas finalizaría la propuesta de Prado y Vallo, otras, con mayor fortuna, imprimirán al casco histórico una nueva morfología urbana. Entre éstas, resaltar una de las más dañosas bajo rúbrica de Pereiro Caeiro en la plaza de Cervantes que supuso el derrumbamiento de un histórico complejo edilicio, constituido por cinco casas de corte barroco y un bonito pazo gótico propiedad de los Vizcondes Torres-Novaes ${ }^{17}$, en el que se enhestará la Casa de

que Santiago tiene que efectuar continuamente en las calles, debido a la circulación de carros, que desnivelaban las losas y originaban continuamente baches, dificultando el tránsito. Los perjuicios eran mayores en invierno, cuando se producía el estancamiento del agua en las calles".

${ }^{13}$ Carlos Martí ARís, "La ciudad histórica...", pág. 35.

${ }^{14}$ Téngase presente que en esta época todavía estaba muy presente el plan hipodámico de Ildefonso Cerdá para Barcelona (1859). Vid. Fernando de Terán Troyano, "Presentación de la edición facsímil del plano de los alrededores de Barcelona y proyecto de su reforma y Ensanche, obra de Ildefonso Cerdá (1859)", Boletín de la Real Academia de Bellas Artes de San Fernando, 108, (2009), págs. 211-212.

${ }^{15}$ Jesús Ángel Sánchez García, "Os séculos XIX e XX" en Fontes escritas para a historia da arquitectura e do urbanismo en Galicia. (Séculos XIX-XX), Santiago, Xunta de Galicia, 2000, pág. 1183.

${ }_{16}^{16}$ Id.

${ }^{17}$ Francisco Singul LoRenzo, "Urbanismo e proxecto urbano na Compostela do século XIX", en Historia Nova IV, Santiago, Asociación galega de historiadores, 1996, págs. 117-118. 
Cambios de Don Olimpio Pérez ${ }^{18}$; un desacorde edificio ecléctico de soportal adintelado con tres alturas ornamentado con balcones y forjas.

De mayor relevancia cabría considerar la obra para la creación de una plaza de mercado ejecutada en los terrenos antiguamente ocupados por el pazo de Altamira en el llamado Picho da Cerca. Proyecto que, si bien se remonta a 1851, no fructificará hasta la década de los setenta, momento en el cual, el arquitecto Agustín Gómez Santamaría firmará los planos definitivos ${ }^{19}$. Con ello, solidificará la operación de cirugía urbana más importante del momento remodelándose el área circunscrita a la calle de Altamira, San Fiz, y el convento de San Agustín. Tan ardua empresa, contará con la colaboración de los más afamados arquitectos del momento. Es así como Manuel de Prado y Vallo realizará las edificaciones colindantes al mercado, —en parte para rentabilizar con su venta tan vasta obra-, conjuntamente a los trazos y alineaciones ejecutadas por Daniel Vahamonde y Antonio Bermejo y Arteaga ${ }^{20}$.

Entre tanto, la ciudad histórica vendría a sufrir una suerte de monumentalización universitaria ${ }^{21}$ —iniciada con la reforma del Edificio Universitario (1889) por Ricardo Velázquez Bosco 22 , y finalizada con la implantación de la Facultad de Medicina (1928) ${ }^{23}$ a cargo de Fernando Arbós y Tremanti- que ayudará, en mucho, al asentamiento de la ciudad como epicentro del saber gallego [figs. 2-3].

Otras intervenciones menos agresivas serán las que tengan como finalidad la creación de espacios verdes insertos en la ciudad vieja. Concienciada la sociedad de que las angostas calles compostelanas contribuían a una cierta opresión vial, pronto se empezará a ver en las plazas la solución a tan molesto encorsetamiento espacial, por lo que no se dudará a la hora de embellecerlas y naturalizarlas a modo de respiraderos en los que vendrían a desembocar un sinfín de estrechos afluentes urbanos ${ }^{24}$. En 1884, Faustino Domínguez se encargará de la realización de un jardín ubicado en la llamada Plaza de la Inmaculada, —entre la fachada

\footnotetext{
${ }_{18}$ José Luís Cabo Villaverde y Pablo Costa Buján, Unha cidade de pedra nas vellas fotografías, Santiago, COAG, 1992, pág. 92.

${ }^{19}$ Francisco Singul Lorenzo, "Urbanismo e proxecto...", pág. 120.

${ }^{20}$ José Luís Cabo Villaverde y Pablo Costa Buján, Unha cidade..., pág. 22.

${ }^{21}$ Ramón Villares, "La ciudad de los Apóstoles...", págs. 503-504.

${ }^{22}$ Alfredo Vigo Trasancos, "Galicia no horizonte de 1909: ciudades e arquitecturas para unha época de esplendor burgués", en Carlos García Martínez, María Méndez García, Isabel Romaní Fariña (Eds.), Exposición galega de 1909: conmemoración do $1^{\circ}$ centenario Exposición Regional Gallega, Santiago 1909, Santiago de Compostela, Consorcio de Santiago, Museo do Pobo Galego e Instituto de Estudios Galegos "Padre Sarmiento", 2010, pág. 36.

${ }^{23}$ Alfredo Vigo Trasancos, "La Imagen de la ciudad y la diversidad estilística: la arquitectura gallega en la época de Canalejas (1870-1912)", en Congreso José Canalejas e a sua época: actas do Congreso en Ferrol, Santiago de Compostela, Xunta de Galicia, 2005, pág. 102.

${ }^{24}$ María del Pilar Cores Trasmonte, El urbanismo en Santiago..., pág. 38.
} 
TRANSFORMACIONES ARQUITECTÓNICAS Y URBANAS EN LA CIUDAD DE SANTIAGO DE COMPOSTELA: EL TRIUNFO DEL GUSTO ECLÉCTICO Y LOS CRITERIOS HIGIENISTAS (1868-1931)

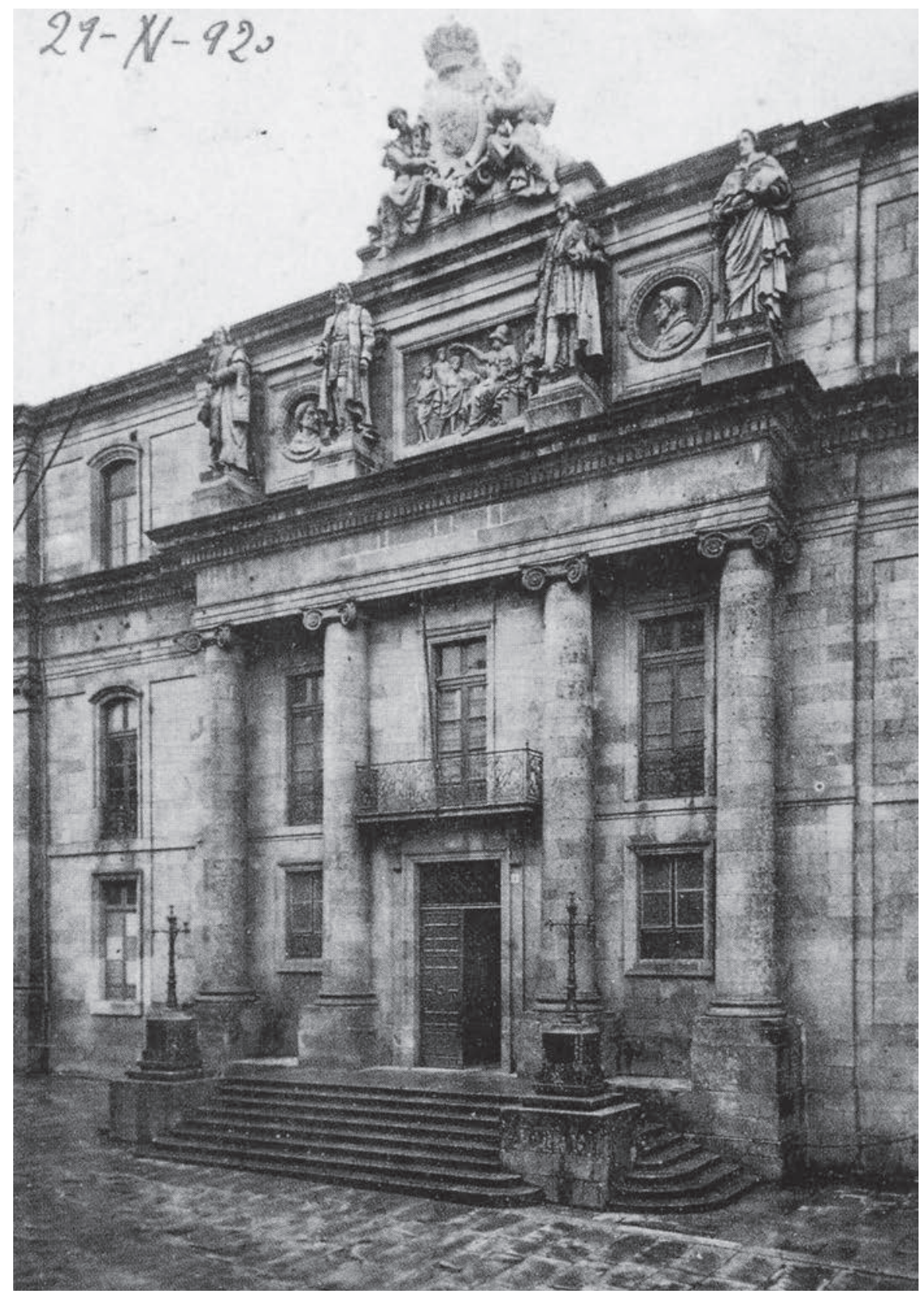

Fig. 2. Ricardo Velázquez Bosco. Reforma del Edificio Universitario. 1889. En: Xosé Manuel García Iglesias, Tarxetas Postais, Santiago de Compostela, Gran Enciclopedia Galega, 1989, pág. 317. 


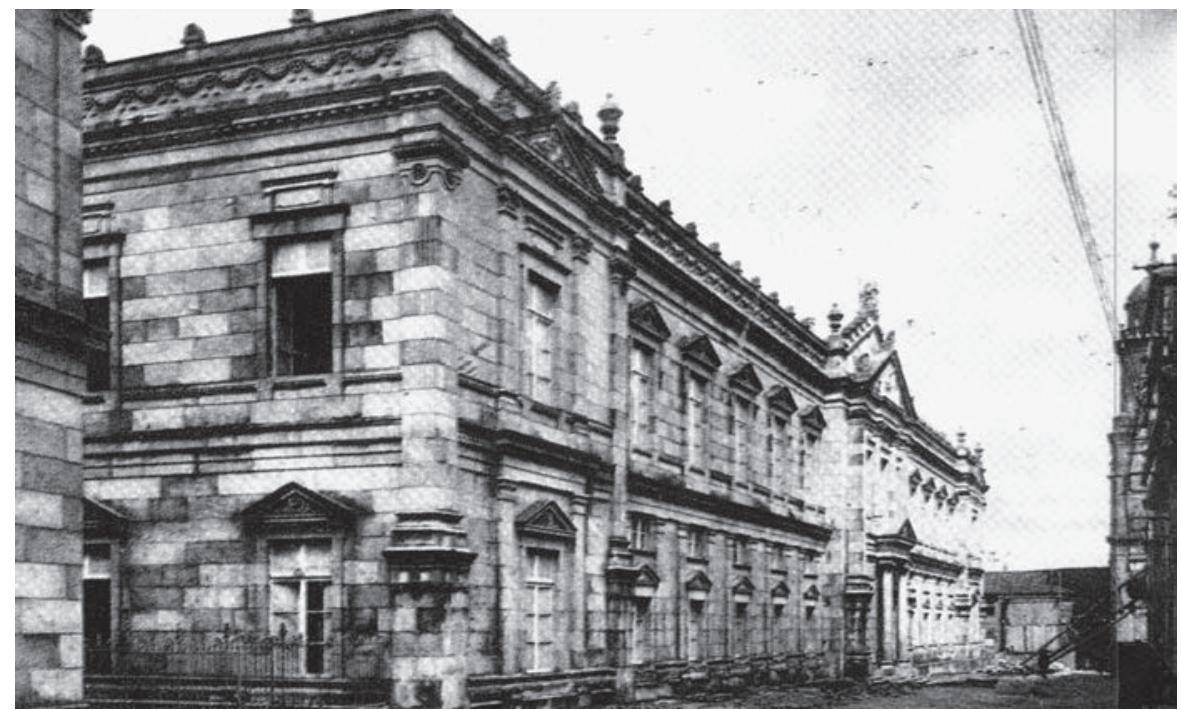

Fig. 3. Fernando Arbós y Tremanti. Construcción de la Facultad de Medicina. 1928. En: Xosé Manuel García Iglesias, Tarxetas Postais, Santiago de Compostela, Gran Enciclopedia Galega, 1989, pág. 323.

de la Azabachería de la Catedral y la portada principal del monasterio de San Martín Pinario_- ${ }^{25}$, que vendría a reaprovechar un espacio originario del XVIII surgido tras la obligatoriedad impuesta por del Cabildo de la creación de una plaza intermedia entre la fachada catedralicia y la monacal ${ }^{26}$.

A partir de entonces, la creación de espacios ajardinados, se convertirá en una constante que fructificará en la aparición de un espléndido jardín entre el Franco y Fonseca (1886) previo derrumbe de las edificaciones ubicadas en su margen Sur, o la omnipresencia arbórea que inundará gran parte de los focos compostelanos, como los vistos en la Plaza de la Quintana, San Roque, o la Plaza de Mazarelos $^{27}$ [fig. 4].

\section{ESPACIOS EXTRAMUROS}

Hasta el momento, la ciudad periférica estaba conformada por dispersos barrios - en su mayoría de origen medieval- configurados perpendicularmente a las puertas de la muralla o en paralelo a los lienzos de la cerca $^{28}$. A finales del

\footnotetext{
${ }^{25}$ Francisco Singul Lorenzo, "Urbanismo e proxecto...", pág. 114.

${ }^{26}$ María del Pilar Cores Trasmonte, El urbanismo en Santiago..., pág. 39.

${ }^{27}$ Íd.

${ }^{28}$ José Luís Cabo Villaverde, Pablo Costa Buján, Unha cidade..., pág. 23.
} 
TRANSFORMACIONES ARQUITECTÓNICAS Y URBANAS EN LA CIUDAD DE SANTIAGO DE COMPOSTELA: EL TRIUNFO DEL GUSTO ECLÉCTICO Y LOS CRITERIOS HIGIENISTAS (1868-1931)

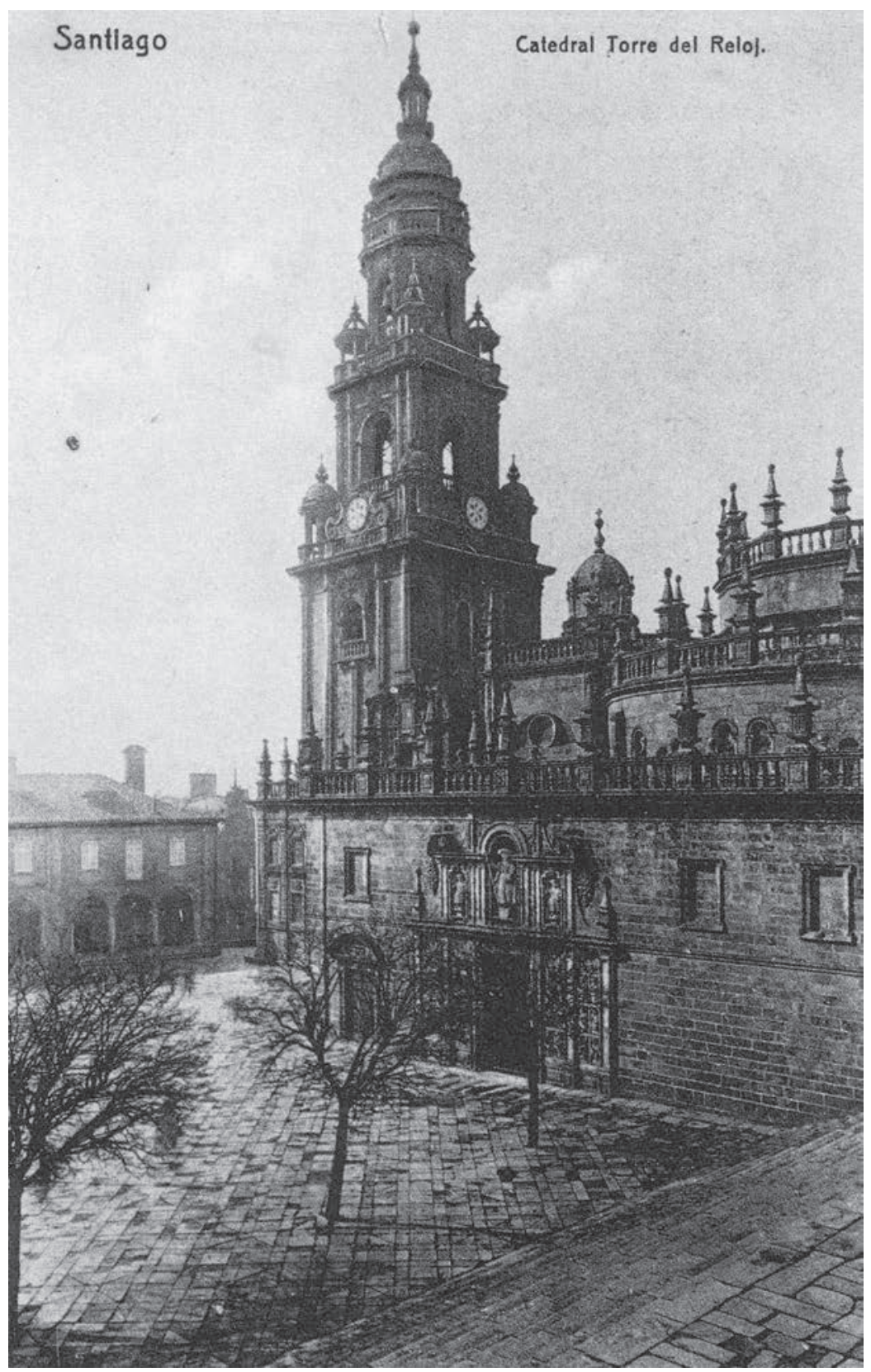

Fig. 4. Arboleda de la Plaza de la Quintana. Ca. 1920. En: José Luís CABo Villaverde, Pablo Costa Buján, Imaxe de Compostela. Unha cidade de pedra nas vellas fotografías, Santiago de Compostela, COAG, 1992, pág. 1. 


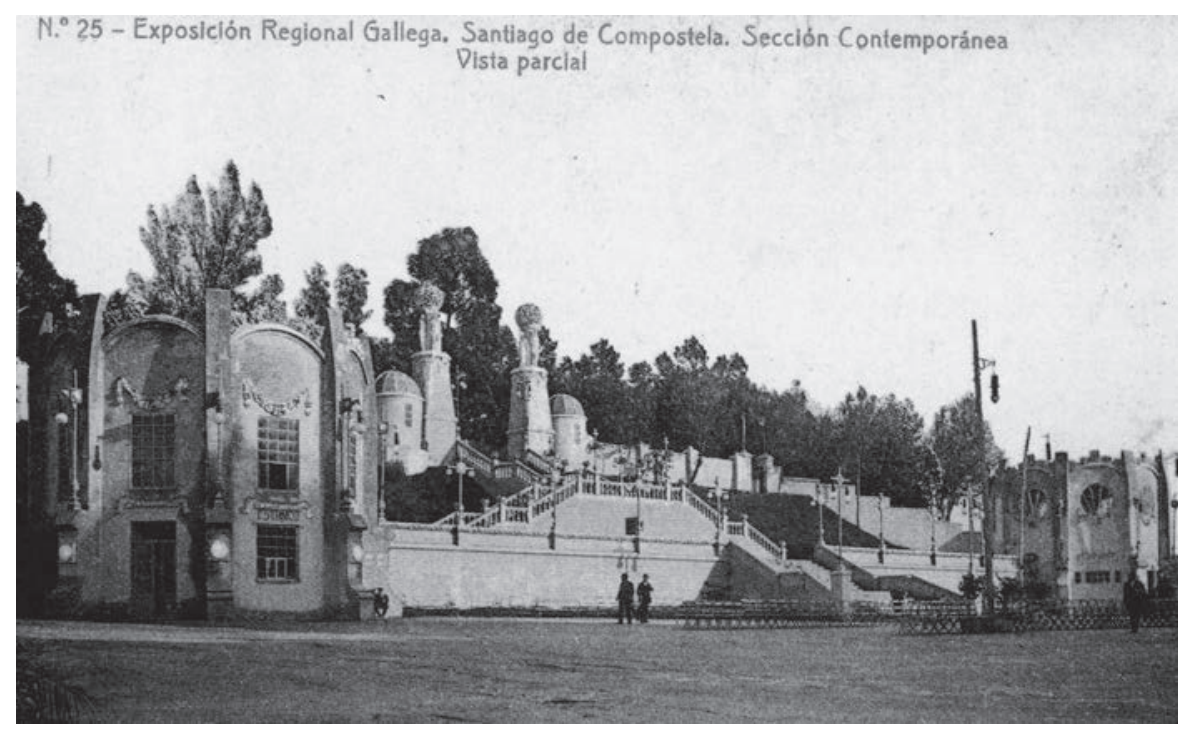

Fig. 5. Exposición Regional. 1909. En: Xosé Manuel García Iglesias, Tarxetas Postais, Santiago de Compostela, Gran Enciclopedia Galega, 1989, pág. 399.

XIX, la muralla se encontraría representada únicamente por la puerta de Mazarelos, tras ser derruidas las restantes entre los años centrales y concluyentes de siglo XVIII, e iniciales del $\mathrm{XIX}^{29}$. Las razones de su desaparición se tornan varias: estado ruinoso de su estructura, restitución por otras arquitecturas, aunque, quizás, la razón imperante, sea la de considerar a la susodicha como un obstáculo vial que vendría a congestionar la comunicación entre la ciudad histórica y los asentamientos periféricos.

Una vez aclarado esto, veamos, pues, cuáles fueron los cambios que allí se produjeron. Comencemos con las modificaciones llevadas a cabo en la Alameda. En el primer tercio del ochocientos y, a la luz de un emergente romanticismo, se acuerda la construcción de un magnífico jardín-alameda, llamado a ultimarse de manera magistral en los últimos años de la centuria ${ }^{30}$. Pertenecientes a esta

\footnotetext{
${ }^{29} I d$. "Con el acuerdo de derribo de la Porta da Pena en 1743 empieza una cadencia que durante cien años condujo a la desaparición de todas ellas, excepto la de Mazarelos, salvada gracias a la presión de los vecinos. Cayeron bajo la piqueta, la de las Huertas al construirse el Palacio de Raxoi, la de San Francisco, la del Camino en sus dos fases de 1800 y 1835, la de la Mámoa en 1801, la de San Roque en 1822 y la de Faxeiras a mediados de siglo". Según Andrés Rosende Valdés, la puerta de San Roque desaparecería en 1801.Vid. Andrés Rosende Valdés, Unha historia urbana: Compostela 1595-1780, Santiago, Edicións Nigra Trea, S. L, 2004, pág. 78.

${ }^{30}$ Xosé Manuel García Iglesias, Tarxetas Postais, Santiago, Gran enciclopedia galega, 1989, pág. 325.
} 


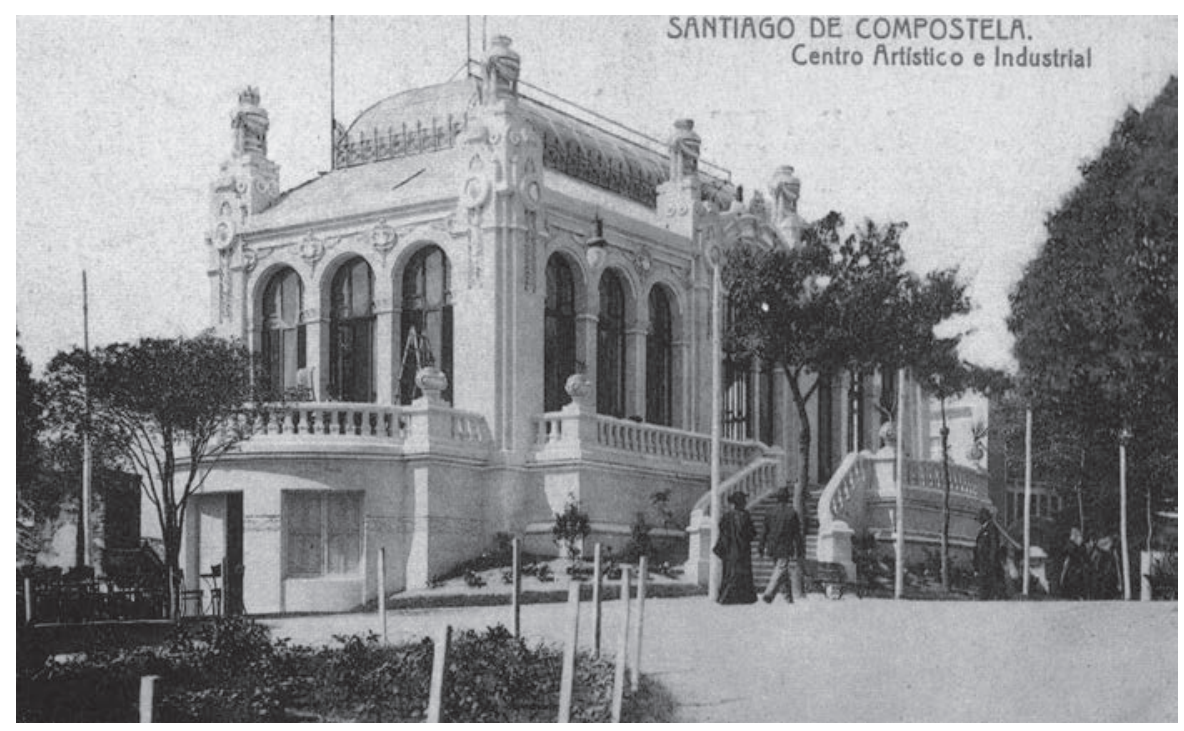

Fig. 6. Exposición regional. 1909. En: Xosé Manuel García Iglesias, Tarxetas Postais, Santiago de Compostela, Gran Enciclopedia Galega, 1989, pág. 397.

etapa, caben reseñarse cuatro intervenciones de especial relevancia vinculadas a la reforma de los caminos: los paseos de París, Madrid y Ferradura, la reforma de la explanada del Campo da Estrela $^{31}$, la construcción de bancos de descanso, nuevas verjas y un kiosco musical ${ }^{32}$, o la dotación de una nueva estatuaria conmemorativa como la de Méndez Núñez realizada por Xoán Sanmartín ${ }^{33}$. Mención aparte, merece la — casi en su totalidad efímera ${ }^{34}$ - Exposición Regional de 1909 que, entre otras cosas, supuso la regularización de explanadas, el levantamiento de nuevas arquitecturas publicitarias ${ }^{35}$ y la apertura de nuevas calles [figs. 5-6]. Respecto a esta última, cabría reseñarse una especialmente importante, la gran escalera — actualmente desaparecida- que por primera vez,

\footnotetext{
${ }^{31}$ José Luís Cabo Villaverde, Pablo Costa Buján, Unha cidade..., pág. 23.

${ }^{32}$ Francisco Singul Lorenzo, "Urbanismo e proxecto...”, pág. 132.

33 Xosé Manuel García Iglesias, Tarxetas..., pág. 325.

${ }^{34}$ José Luís Cabo Villaverde, Pablo Costa Buján, Unha cidade..., pág. 33. "La aparente solidez de las construcciones, que puede deducirse de los documentos gráficos que exponemos, enmascara unas arquitecturas en su mayoría de cartón piedra, efímeras, ejecutadas con gran rapidez —el Pabellón de la Habana se construyó en veinte días- y mayor escasez de medios. Básicamente, estaban construidas en su parte estructural por ladrillos y maderas, sufriendo con prontitud las consecuencias del riguroso clima gallego. En efecto, con las primeras lluvias aparecen goteras y con los primeros vientos se desprenden decorados o se desploma algún pabellón a los pocos días de su inauguración, como el perteneciente al Ministerio de Fomento". ${ }^{35} I d$.
} 


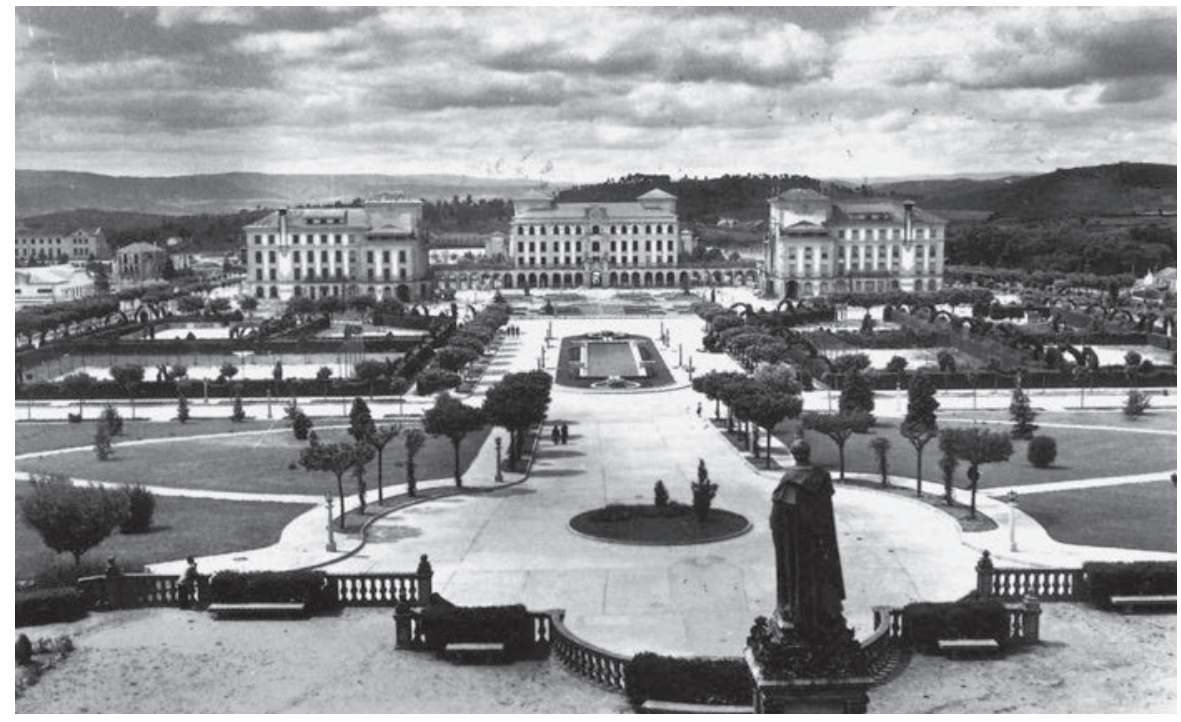

Fig. 7. Constantino Candeira y Jenaro de la Fuente. Vista panorámica de la Residencia de Estudiantes. 1929. En: Xosé Manuel García Iglesias, Tarxetas Postais, Santiago de Compostela, Gran Enciclopedia Galega, 1989, pág. 323.

comunicará el paseo de la Herradura con el llamado Agro do Mendo (actual Residencia Universitaria). Dicha traza, vendría a cimentar las bases de lo que, años más tarde, se constituiría como uno de los proyectos más ambiciosos de la Compostela contemporánea: la Residencia de Estudiantes ${ }^{36}$. Es así, como tras la desaparición de nueve de los edificios pertenecientes a la exposición regional, empieza a formalizarse un plan para la construcción de un conjunto integrador acorde a la nueva demanda universitaria. Plan que, al amparo de los felices años veinte, fructificará en la elaboración de las trazas, a cargo del por entonces arquitecto municipal Constantino Candiera que será relevado por Jenaro de la Fuente posteriormente. A grosso modo, el proyecto consistía en la creación de una gran plaza abrazada por cinco edificios con Stadium, circundados por diversas y grandes áreas ajardinadas ${ }^{37}$ [fig. 7].

De manera sincrónica, se llevará a cabo la realización de un Ensanche compostelano. Éste, como tal, se remontará en origen a finales del siglo XIX, momento en el que se concretarán los límites de acción de tan vasta intervención en los terrenos llamados Agros de Carreira (actual Plaza de Galicia y Montero

\footnotetext{
${ }^{36}$ Ramón Villares, La ciudad de los Apóstoles..., pág. 514.

${ }^{37}$ Íd.
} 


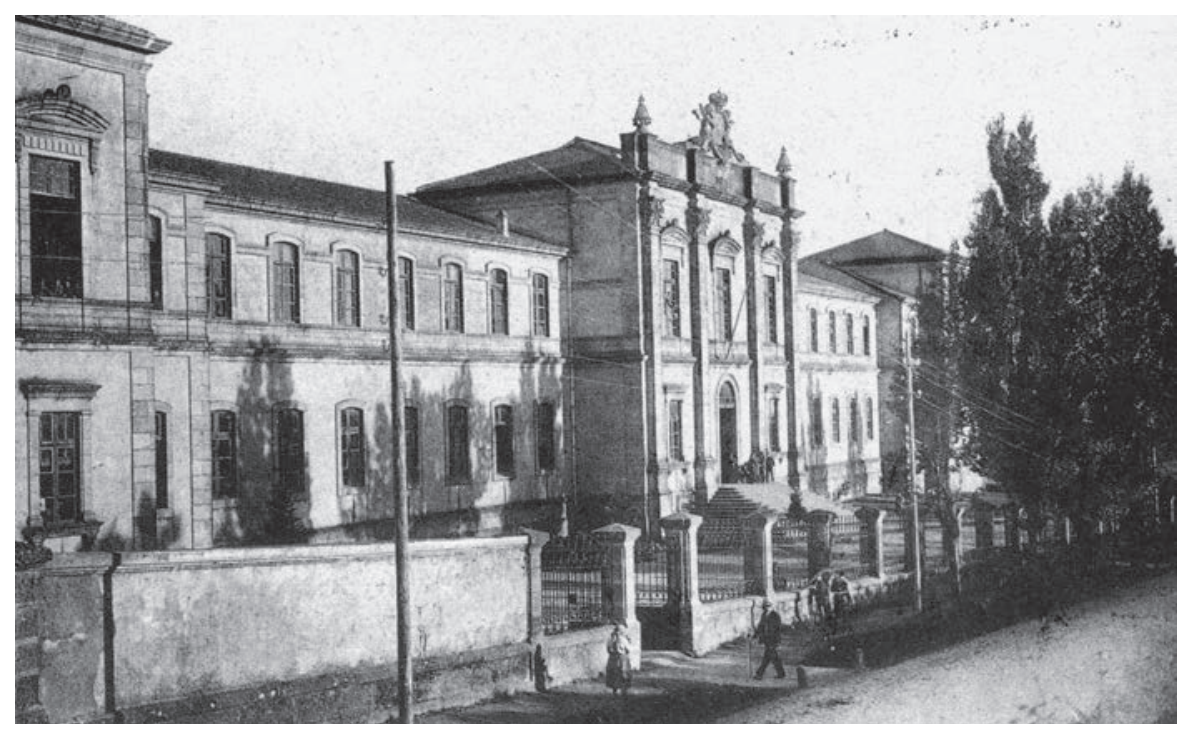

Fig. 8. Antonio Bermejo y Arteaga. Escuela de Veterinaria. 1915. En: Xosé Manuel García Iglesias, Tarxetas Postais, Santiago de Compostela, Gran Enciclopedia Galega, 1989, pág. 291.

Ríos $)^{38}$. Sin embargo, no será hasta el primer tercio del siglo XX cuando se lleve a cabo una adecuada ordenación urbana, tras el inicial Plano de la Población (1907) ideado por los ingenieros Ramón Laforet, Enrique Cánovas y José de la Gándara, que concluirá con el llamado Plan de ordenación del Ensanche $(1928)^{39}$. La premisa no era otra que proceder a una reordenación zonal, constituida por una serie de edificios dispuestos de manera anárquica, que tras la petición de un sinfín de licencias, irían configurando un crecimiento urbano desorganizado. Con todo, previamente al plan de 1928, fueron numerosos los hechos que contribuyeron al crecimiento de la ciudad en dirección SO, destacándose entre ellos, el establecimiento de la estación ferroviaria de Cornes, el

\footnotetext{
${ }^{38}$ Vid. A.M.S. Obras y Urbanismo. Alineaciones. Expediente y proyecto facultativo para la nueva alineación de la calle del Órreo de esta ciudad. 1863; A.M.S. Obras y Urbanismo. Alineaciones. Plano geométrico de alineación de las dos aceras del primer tramo de la calle del Hórreo. 1880; A.M.S. Obras y Urbanismo. Obras, Aceras y Empedrados. Expediente instruido para la construcción de la escalinata que desde la calle de la Senra dé acceso á la carretera que dirija a Pontevedra. 1883; A.M.S. Obras y Urbanismo. Obras, Aceras y Empedrados. Plano de alineaciones geométricas, rasantes, y perfil transversal de la calle Carrera del Conde. 1904; A. M. S. Gobierno. Ordenanzas Municipales. 1907. Art. 47.

${ }^{39}$ Rafael Baltar Tojo, Arquitectura y preexistencias una referencia gallega, A Coruña, Edicións do Castro, 1991, pág. 52.
} 


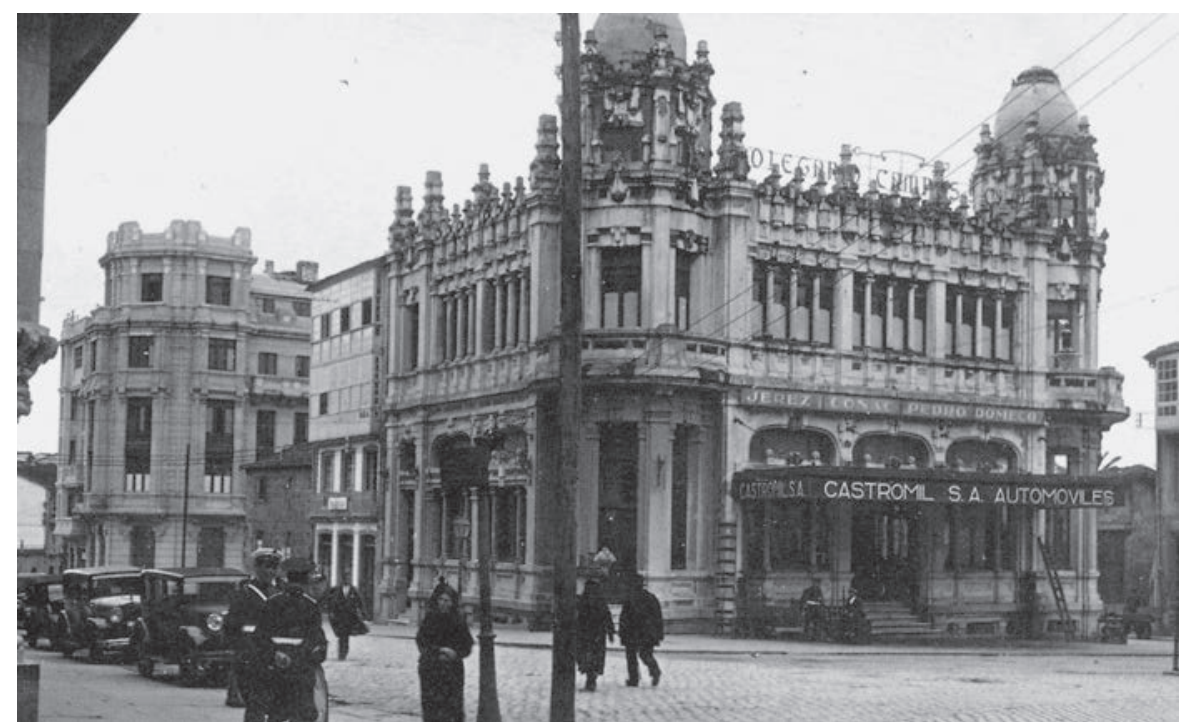

Fig. 9. Rafael González Villar. Edificio Castromil. 1922. En: Xosé Manuel García IgLesIaS, Tarxetas Postais, Santiago de Compostela, Gran Enciclopedia Galega, 1989, pág. 289.

levantamiento de la Escuela Veterinaria (1915) (actual Palamento de Galicia) ${ }^{40}$ [fig. 8], o la anexión de la ciudad al barrio de Conxo a Santiago (1925) ${ }^{41}$. Por no hablar de la ubicación de dos de los monumentos - actualmente desaparecidos - más espectaculares: la barroca Casa de la Inquisición ${ }^{42}$ de Fernando de Casas, demolida en 1913, y como no, el edificio Castromil de Rafael González Villar, que desde su creación en 1922, presidirá el Ensanche compostelano hasta su desaparición en $1974^{43}$ [fig. 9].

De manera análoga, y a la sombra del desarrollo SO, se desarrollará la zona NE compostelana, sin duda, propiciada por cuatro intervenciones urbanas surgidas al calor del siglo XIX y de las décadas iniciales del $\mathrm{XX}^{44}$. Por este orden son: la demolición de la antigua puerta de San Roque $(1822)^{45}$, que contribuirá a la hibridación del casco antiguo con las áreas aledañas, la reconversión del camino

\footnotetext{
${ }^{40}$ Iván Moure Pazos, La ciudad de Santiago y las Escuelas de Veterinaria y Sordomudos y Ciegos: desarrollo urbano de un nuevo orden académico (1864-1925), Universidad de Santiago, Tesis de licenciatura inédita, 2009, págs. 35-119.

${ }^{41}$ Ramón Villares, La ciudad de los Apóstoles..., pág. 553.

${ }^{42}$ Ubicada donde actualmente se encuentra el Hotel Compostela.

${ }^{43}$ Demolido tras el acuerdo de establecer un estacionamiento subterráneo en su solar.

${ }^{44}$ José Luís Pereiro Alonso, Rincones de Compostela. La obra de Manuel Pereiro Caeiro, Santiago, Universidad de Santiago, 1996, págs. 162-167.

45 José Luís Cabo Villaverde, Pablo Costa Buján, Unha cidade..., pág. 23.
} 


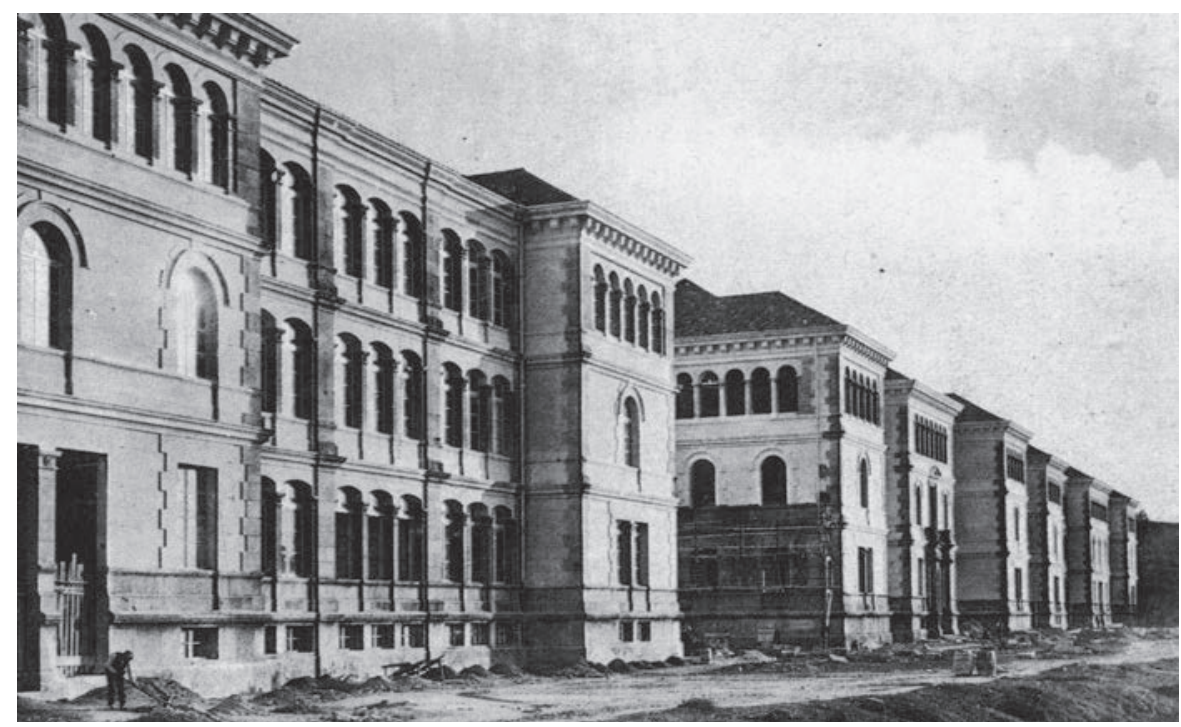

Fig. 10. Ricardo Velázquez Bosco. Escuela de Sordomudos y Ciegos. 1925. En: Xosé Manuel García Iglesias, Tarxetas Postais, Santiago de Compostela, Gran Enciclopedia Galega, 1989, pág. 291.

de Sta. Clara en carretera $(1840)^{46}$, comunicando Santiago con A Coruña, el adecentamiento y arbolado de dicha carretera $(1885)^{47}$ y la expansión vial propiciada por la construcción de la Escuela de Sordomudos y Ciegos en el barrio de San Caetano (1905-1925) (actual Xunta de Galicia) a cargo del arquitecto Ricardo Velázquez $\operatorname{Bosco}^{48}$ [fig. 10].

\section{CONCLUSIONES}

Tras un sucinto recorrido por las principales intervenciones urbanas acaecidas en la Compostela finisecular entre 1868 y 1931, parece ineludible constatar que la ciudad se vio inmersa en un sinfín de modificaciones que tuvieron como denominador común la salubridad a través de la creación de nuevos espacios. La oxigenación de arterias viales, mediante la destrucción de la vieja muralla intra-

\footnotetext{
${ }^{46}$ Francisco Singul Lorenzo, "Urbanismo e proxecto...", pág. 128.

${ }^{47}$ Íd.

${ }^{48}$ Iván Moure Pazos, "El proyecto de Ricardo Velázquez Bosco para Santiago de Compostela: la Escuela de Sordomudos y Ciegos (1905-1925)", Ars Longa, 20 (2011), págs. 173-182; Margarita Barral Martínez, Eugenio Montero Ríos e a Cidade de Santiago, Santiago, Universidad de Santiago de Compostela, 2005, pág. 251; Miguel Ángel Baldellou Santolaria, Ricardo Velázquez Bosco, Madrid, Ministerio de Cultura, 1990, pág. 344.
} 
muros, la extirpación de soportales, o la creación de áreas ajardinadas, supusieron, en gran medida, la mutilación del viejo trazado medieval. De igual forma, el desarrollo zonal extramuros se desarrolló en base a esta premisa esencial. Es así como, para la creación de grandes escuelas — focos infecciosos por antonomasia- se consideraron idóneos, terrenos por entonces periféricos. Análoga suerte siguieron los nuevos cementerios. De todos modos, no ha de descuidarse un segundo factor condicionante, sin menoscabo del higiénico, que influyó, de manera considerable, en dicha transformación: el imperante gusto ecléctico. Santiago, aun siendo una ciudad refractaria a la modernidad, introduce en su catálogo arquitectónico auténticas joyas del eclecticismo de época. Me asalta como ejemplo, La Escuela de Veterinaria (1915) de Antonio Bermejo y Arteaga, creada a imagen y semejanza de L'École d'Anatomie d'Alfort (1882) de Diet en París $^{49}$, o el prolífico recetario edilicio ofrecido a lo largo de esta investigación entre 1868 y 1931.

A modo de resumen, puede concluirse, que el Santiago de fines del XIX y principios del XX, sacrifica gran parte de su asentamiento medieval y barroco en pos de un nuevo orden urbano cimentado en base a dos criterios fundamentales, uno explícito y otro implícito: el gusto arquitectónico, y el criterio médico. Criterios que han incidido, de manera decisiva, tanto en la dilatación espacial de su callejero como en la liberación tectónica de la ciudad contemporánea.

\section{BiBLIOGRAFÍA}

Baldellou Santolaria, Miguel Ángel, Ricardo Velázquez Bosco, Madrid, Ministerio de Cultura, 1990.

Baltar Tojo, Rafael, Arquitectura y preexistencias una referencia gallega, A Coruña, Edicións do Castro, 1991.

Barral Martínez, Margarita, Eugenio Montero Ríos e a Cidade de Santiago, Santiago, Universidad de Santiago de Compostela, 2005.

Beiras García, Eduardo, El arte del agua. Compostela y sus fuentes públicas monumentales de la edad media al siglo XX, A Coruña, InEditor, 2012.

Bonet Correa, Antonio, "Las ciudades gallegas en el siglo XIX", en María Victoria Carballo Calero (coord.), Arte y Ciudad. Ámbitos medieval, moderno y contemporáneo, Santiago, Fundación Caixa Galicia, 2000, págs. 180-189.

Bonet Correa, Antonio, Figuras, modelos e imágenes en los tratadistas españoles, Madrid, Alianza Editorial, S. A., 1993.

Bonet Correa, Antonio, El urbanismo en España e Hispanoamérica, Madrid, Cátedra, 1991.

\footnotetext{
${ }^{49}$ Iván Moure Pazos, "El gran proyecto de Antonio Bermejo y Arteaga para Santiago de Compostela: la Escuela de Veterinaria como émula de la École d'anatomie d'Alfort en París", Cuadernos de Estudios Gallegos, 124 (2011), págs. 253-273. En dicho trabajo, se relaciona a La Escuela Veterinaria de Santiago con L'École d'anatomie d'Alfort de Diet en París.
} 
TRANSFORMACIONES ARQUITECTÓNICAS Y URBANAS EN LA CIUDAD DE SANTIAGO DE COMPOSTELA: EL TRIUNFO DEL GUSTO ECLÉCTICO Y LOS CRITERIOS HIGIENISTAS (1868-1931)

Bonet Correa, Antonio, La historiografía urbana en España, Extremadura, Universidad de Extremadura, 1987.

Cabo Villaverde, José Luís y Costa Buján, Pablo, Unha cidade de pedra nas vellas fotografías, Santiago, COAG, 1992.

Cores Trasmonte, María del Pilar, El urbanismo en Santiago de Compostela en el siglo XIX, Santiago, Universidad de Santiago, 1962.

Costa Buján, Pablo y Morenas Aydillo, Julián, Santiago de Compostela. 1850-1950, Santiago, COAG, 1989.

Durán Villa, Francisco, Fernández Fernández, Carlos y Sánchez García, Jesús Ángel, “Asilos de la muerte. Higiene, sanidad y arquitectura en los cementerios gallegos del siglo XIX", Semata, 17 (2006), págs. 435-472.

Fernández Fernández, Xavier, Arquitectura del eclecticismo en Galicia (1875-1914), A Coruña, Universidad de Coruña, 1996.

García Iglesias, Xosé Manuel, Tarxetas Postais, Santiago, Gran enciclopedia galega, 1989.

García Filgueira, Marta, Eclecticismo y arquitectura en la Galicia del siglo XIX. La obra de Domingo Rodríguez Sesmero y Alejandro Rodríguez, Sesmero González, Santiago, Universidad de Santiago de Compostela, 2006.

Hernando, Javier, La Arquitectura en España (1770-1900), Madrid, Cátedra, 1989.

Martí Arís, Carlos, "La ciudad histórica como presente" en Carlos Martí Arís (ed.), La ciudad histórica como presente. Un recorrido por la arquitectura de Santiago, Consorcio de Santiago, Santiago, 1995, pág. 34.

Monterroso Montero, Juan, "El centro histórico. La creación de una conciencia cultural. El caso de Santiago de Compostela", Actas do seminario: Centros históricos: pasado e presente, Oporto, Faculdade de letras da universidade do Porto, 2011, págs. 39-69.

Moure Pazos, Iván, La ciudad de Santiago y las Escuelas de Veterinaria y Sordomudos y Ciegos: desarrollo urbano de un nuevo orden académico (1864-1925), Universidad de Santiago, Tesis de licenciatura inédita, 2009.

Moure Pazos, Iván, "El proyecto de Ricardo Velázquez Bosco para Santiago de Compostela: la Escuela de Sordomudos y Ciegos (1905-1925)", Ars Longa, 20 (2011), págs. 173-182.

Moure Pazos, Iván, "El gran proyecto de Antonio Bermejo y Arteaga para Santiago de Compostela: la Escuela de Veterinaria como émula de la École d'anatomie d'Alfort en París", Cuadernos de Estudios Gallegos, 124 (2011), págs. 253-273.

Pereiro Alonso, José Luís, Rincones de Compostela. La obra de Manuel Pereiro Caeiro, Santiago, Universidad de Santiago, 1996.

Pérez Constanti, Pablo, Notas Viejas Galicianas, Santiago, Xunta de Galicia, 1993.

Pérez Lugín, Alejandro, La casa de la Troya, Santiago, Universidad de Santiago, 2008.

Rosende Valdés, Andrés, Unha historia urbana: Compostela, 1595-1780, Santiago, Edicións Nigra Trea, S. L., 2004.

Rosende Valdés, Andrés, Compostela (1780-1907): Una aproximación a la ciudad decimonónica, Santiago, Consorcio de Santiago y Teófilo Edicións, 2013. 
Sánchez García, Jesús Ángel, "Os séculos XIX e XX" en Fontes escritas para a historia da arquitectura e do urbanismo en Galicia. (Séculos XIX-XX), Santiago, Xunta de Galicia, 2000, pág. 1183.

Sánchez García, Jesús Ángel, La arquitectura teatral en Santiago de Compostela (17681946), A Coruña, Edicións do Castro, 1993.

Singul Lorenzo, Francisco, "Urbanismo e proxecto urbano na Compostela do século XIX", en Historia Nova IV, Santiago, Asociación galega de historiadores, 1996, págs. 117-118.

Terán Troyano, Fernando de, "Presentación de la edición facsímil del plano de los alrededores de Barcelona y proyecto de su reforma y Ensanche, obra de Ildefonso Cerdá (1859)", Boletín de la Real Academia de Bellas Artes de San Fernando, 108 (2009), págs. 211-212.

Vigo Trasancos, Alfredo, "La Imagen de la ciudad y la diversidad estilística: la arquitectura gallega en la época de Canalejas (1870-1912)", en Congreso José Canalejas e a sua época: actas do Congreso en Ferrol, Santiago de Compostela, Xunta de Galicia, 2005, págs. 95-118.

Vigo Trasancos, Alfredo, "Galicia no horizonte de 1909: ciudades e arquitecturas para unha época de esplendor burgués", en Carlos García Martínez, Rosa María Méndez García e Isabel Romaní Fariña (eds.), Exposición galega de 1909: conmemoración do $1^{o}$ centenario Exposición Regional Gallega, Santiago 1909, Santiago de Compostela, Consorcio de Santiago, Museo do Pobo Galego e Instituto de Estudios Galegos "PadreSarmiento", 2010, págs. 31-78.

Vigo Trasancos, Alfredo,'La Universidad de Santiago de Compostela: ciudad y universidad, 500 años de construcción urbana", en Javier Rivera Blanco (coord.), Restauración contemporánea: ciudades universitarias, ciudades Patrimonio de la Humanidad. La manzana fundacional cisneriana de la Universidad de Alcalá, Alcalá de Henares, Servicio de Publicaciones de la Universidad de Alcalá, 2013, págs. 113-134.

Villares, Ramón, "La ciudad de los dos Apóstoles (1875-1936)", en Ermelindo Portela Silva (coord.), Historia de la Ciudad de Santiago de Compostela, Santiago, Concello de Santiago, 2003, págs. 477-559. 